\title{
Testes de deterioração controlada e envelhecimento acelerado para avaliação do vigor em nabo forrageiro ${ }^{1}$
}

\author{
Tests of controlled deterioration and accelerated ageing to assess vigour in the wild \\ radish
}

\author{
Camila Santos Barros de Morais ${ }^{2 *}$ e Claudia Antonia Vieira Rossetto ${ }^{3}$
}

\begin{abstract}
RESUMO - O objetivo do trabalho foi verificar a eficiência de diferentes procedimentos para condução dos testes de envelhecimento acelerado e deterioração controlada visando avaliação da qualidade fisiológica de sementes de nabo forrageiro (Raphanus Sativus L. var oleiferus). Quatro lotes de sementes de nabo forrageiro da cultivar CATI AL 1000 foram caracterizados inicialmente pelos testes de germinação, primeira contagem, comprimento e massa de plântulas, condutividade elétrica, emergência em areia e campo e índice de velocidade de emergência em areia e campo. Em seguida, foram submetidos aos testes envelhecimento acelerado com ou sem solução saturada de $\mathrm{NaCl}$ sob temperatura de 42 e $45^{\circ} \mathrm{C}$ durante 36 e 48 horas, e aos testes de deterioração controlada com sementes pré-umedecidas a 15; 20 e $25 \%$ sob temperatura de 42 e $45^{\circ} \mathrm{C}$ durante 36 e 48 horas. O teste de envelhecimento acelerado (com solução de $\mathrm{NaCl}$ sob temperatura de $45{ }^{\circ} \mathrm{C}$ durante 36 horas) e o de deterioração controlada (com sementes pré-umedecidas a $20 \%$ sob temperatura de $45^{\circ} \mathrm{C}$ ) durante 36 horas, assim como o de emergência de plântulas em campo, foram eficientes na classificação dos lotes de sementes de nabo forrageiro em quatro distintos níveis de vigor.
\end{abstract}

Palavras-chave: Nabo. Sementes-fisiologia. Sementes-qualidade.

\begin{abstract}
The aim of this study was to verify the efficiency of different procedures for carrying out tests of accelerated ageing and controlled deterioration with a view to evaluate the physiological quality of wild radish seeds (Raphanus Sativus L. var oleiferus). Four lots of wild radish seed, cultivar CATI AL 1000, were first characterized by tests of germination, first count, length and mass of seedlings, electrical conductivity, emergence in sand and soil, and speed-emergence index for sand and soil. They were then submitted to tests of accelerated ageing, both with and without a saturated $\mathrm{NaCl}$ solution, at temperatures of 42 and $45^{\circ} \mathrm{C}$ for 36 and 48 hours, and to tests of controlled deterioration with seeds pre-soaked to 15,20 and $25 \%$, at temperatures of 42 and $45{ }^{\circ} \mathrm{C}$ for 36 and 48 hours. The test for accelerated ageing (with a $\mathrm{NaCl}$ solution at a temperature of $45{ }^{\circ} \mathrm{C}$ for 36 hours) and that for controlled deterioration (with $20 \%$ pre-soaked seeds at a temperature of $45^{\circ} \mathrm{C}$ for 36 hours), as well as the test for seedling emergence in soil, were efficient for the classification of seed lots of the wild radish at four different levels of vigour.
\end{abstract}

Key words: Oil radish. Seed-Physiology. Seed-Quality.

\footnotetext{
*Autor para correspondência

${ }^{1}$ Recebido para publicação em 21/11/2011; aprovado em 16/03/2013

Parte da Tese do primeiro autor defendida na Universidade Federal Rural de

${ }^{2}$ Programa de Pós-Graduação em Fitotecnia/UFRRJ, BR 465 Km 07, Seropédica-RJ, Brasil, 23.890-000, sbcamila@yahoo.com.br

${ }^{3}$ Departamento de Fitotecnia/Instituto de Agronomia/UFRRJ, cavrosse@ufrrj.br
} 


\section{INTRODUÇÃO}

Com a procura de espécies produtoras de óleo não comestível para a produção de biodiesel, o nabo forrageiro vem sendo alternativa interessante aos agricultores (SOUZA et al., 2009). No entanto, para o alcance da produtividade desejada da cultura devem ser utilizadas sementes de elevada qualidade, as quais irão favorecer a germinação mais rápida e uniforme (MARCOS FILHO, 1999).

Para avaliar a qualidade das sementes, além do teste de germinação que apresenta menor sensibilidade em identificar diferenças entre lotes de sementes, uma vez que é realizado em condições favoráveis de temperatura e umidade do substrato, vem sendo sugerida a utilização de testes de vigor (TEKRONY, 2003). Porém, de acordo com Verma, Verma e Tomer (2003), não se deve utilizar somente um teste de vigor, mas a combinação dos testes visando avaliar os diferentes parâmetros fisiológicos e bioquímicos característicos das sementes, que estão relacionados à perda do vigor, bem como situações de tolerância a estresse ambiental. Em regiões tropicais e subtropicais, a rápida deterioração das sementes armazenadas está intimamente ligada à elevada temperatura e umidade relativa do ar. Com isto, a indústria de sementes vem utilizando os testes de vigor como rotina, para selecionar lotes destinados à comercialização, de acordo com o desempenho em campo e também no armazenamento (GOULART; TILLMANN, 2007; MARCO FILHO, 1999). Entre os testes de vigor, principalmente para brássicas, vêm sendo ajustadas metodologias para os testes de envelhecimento acelerado e de deterioração controlada visando avaliar o grau de deterioração das sementes expostas aos estresses de elevada umidade e temperatura do ar. No entanto, para o teste de deterioração controlada, o conteúdo de água das sementes é ajustado a um determinado nível antes de submetê-las a elevada temperatura, de modo a permitir o maior controle do teor de água das sementes durante a deterioração (ROSSETTO; MARCOS FILHO, 1995). Já, para o teste de envelhecimento acelerado, as sementes são expostas ao ambiente com elevada umidade e temperatura, proporcionando com isso, diferença na intensidade e velocidade de absorção de água (MARCOS FILHO; NOVEMBRE; CHAMMA 2001).

Para nabo forrageiro, Nery, Carvalho e Guimarães (2009) verificaram que tanto o teste de envelhecimento acelerado com solução saturada sob $41^{\circ} \mathrm{C}$ por 72 horas como o de condutividade elétrica utilizando 25 sementes em $50 \mathrm{~mL}$ por seis horas foram adequados para separar os lotes em diferentes níveis de vigor. Porem, há necessidade de avaliar a eficiência de outros testes de vigor. Na literatura, tem sido verificado que o teste de deterioração controlada com sementes pré-umedecidas a $20 \%$ sob $45^{\circ} \mathrm{C}$ durante 24 horas foi eficiente na separação de lotes de sementes, de brócolis (MENDONÇA; RAMOS; FESSEL, 2005) e de sementes de repolho (DEMIR et al., 2008) assim como sob temperatura de $41^{\circ} \mathrm{C}$ por 24 horas, de sementes rúcula (GOULART; TILLMANN, 2007). Além disso, este teste apresentou correlação elevada com o teste de emergência a campo, para sementes de canola (LARSEN et al., 1998) e com teste de emergência de sementes de repolho em bandeja (MATTHEWS et al., 2009).

Assim, o objetivo do trabalho foi verificar a eficiência de diferentes procedimentos para condução dos testes de envelhecimento acelerado e deterioração controlada visando avaliação do vigor de sementes de nabo forrageiro em comparação a outros testes de vigor que vêm sendo empregados.

\section{MATERIAL E MÉTODOS}

O trabalho foi conduzido com quatro lotes de sementes de nabo forrageiro (Raphanus sativus L. var oleiferus), da cultivar CATI AL 1000 da safra 2010, retidas em peneira com crivo circular de diâmetro de $2,83 \mathrm{~mm}$. Estes lotes permaneceram armazenados sob temperatura de $17^{\circ} \mathrm{C}$ e $46 \%$ de umidade relativa do ar por dois meses até o inicio das avaliações. O delineamento experimental adotado foi o inteiramente casualizado com quatro repetições, para cada teste empregado, avaliando-se o efeito de lotes. Para isto, primeiramente os quatros lotes foram submetidos aos testes de grau de umidade a $103 \pm 3{ }^{\circ} \mathrm{C}$, durante 17 horas, e de peso de 1.000 sementes (BRASIL, 2009).

Para o teste de germinação, quatro repetições de 50 sementes por lote, foram distribuídas sobre papel tipo germitest umedecido com água destilada na proporção de 2,5 vezes a sua massa, no interior de caixas tipo gerbox, que foram mantidas em germinador sob temperatura de $20-30{ }^{\circ} \mathrm{C}$ em ausência de luz. As avaliações foram realizadas aos quatro e 10 dias (BRASIL, 2009), sendo consideradas como plântulas normais, as que apresentavam comprimento superior a $2,0 \mathrm{~cm}$, e com todas as estruturas desenvolvidas. Os resultados foram expressos em porcentagem. O teste de primeira contagem foi realizado considerando o número de plântulas normais ao $4^{\circ}$ dia do teste de germinação. Os resultados foram expressos em porcentagem.

No teste de comprimento e massa seca de plântulas, quatro repetições de 10 sementes por lote foram dispostas sobre três folhas de papel germitest no interior de caixas do tipo gerbox, a $20-30^{\circ} \mathrm{C}$, em ausência de luz. As plântulas normais foram avaliadas ao $4^{\circ}$ dia após a instalação, medindo-se o comprimento da extremidade da raiz até a inserção dos cotilédones (NAKAGAWA, 1999). 
Posteriormente, raiz e hipocótilo foram colocados em sacos de papel e levados à estufa de circulação de ar sob $65^{\circ} \mathrm{C}$, até a obtenção de massa constante. Os resultados foram expressos em cm planta $^{-1}$ e mg planta ${ }^{-1}$.

O teste de condutividade elétrica foi realizado com quatro repetições de 25 sementes por lote. As sementes foram imersas em $50 \mathrm{~mL}$ de água destilada (NERY; CARVALHO; GUIMARÃES, 2009) e mantidas sob temperatura de $20{ }^{\circ} \mathrm{C}$ durante 24 horas (TORRES; PEREIRA, 2010). As leituras de condutividade elétrica foram realizadas por condutivímetro digital da marca Quimis G795P. Os resultados foram expressos em $\mu \mathrm{S} \mathrm{cm}^{-1} \mathrm{~g}^{-1}$.

$\mathrm{O}$ teste de emergência em areia foi realizado em caixas plásticas $(20,5 \times 13,5 \times 5,5 \mathrm{~cm})$, contendo $0,5 \mathrm{~kg}$ de substrato de areia lavada, esterilizada (em autoclave a $120^{\circ} \mathrm{C}$ por 2 horas) e umedecida com água destilada, visando atingir $60 \%$ da capacidade de retenção, com base em Brasil (2009). Foram distribuídas quatro repetições de 50 sementes por lote. As avaliações foram realizadas diariamente até os 21 dias após a instalação (NAKAGAWA, 1999). Os resultados foram expressos em porcentagem e em índice de velocidade de emergência.

$\mathrm{O}$ teste de emergência a campo foi realizado com quatro repetições de 50 sementes por lote, distribuídas em um metro linear em solo classificado como Planossolo, em novembro de 2010. As avaliações foram realizadas, diariamente, até os 21 dias (NAKAGAWA, 1999). Os resultados foram expressos em porcentagem de emergência e índice de velocidade de emergência.

Para o teste de envelhecimento acelerado, foram utilizadas 250 sementes (2,80 g) por lote. As sementes foram dispostas em camada única sobre tela de alumínio no interior de caixas plásticas do tipo gerbox, contendo ou não $40 \mathrm{~mL}$ de solução saturada de $\mathrm{NaCl}\left(40 \mathrm{~g} 100 \mathrm{~mL}^{-1}\right)$ no fundo e mantidas sob temperatura de $42{ }^{\circ} \mathrm{C}$ (COSTA; TRZECIAK; VILLELA, 2008) e de $45^{\circ} \mathrm{C}$ (KIKUTI; MARCOS FILHO, 2008), durante 36 horas, com base em Costa, Trzeciak e Villela (2008) e durante 48 horas. Posteriormente foram instalados os testes de grau de umidade e de germinação, considerando apenas a primeira contagem. Os resultados foram expressos em porcentagem.

No teste de deterioração controlada, para cada lote, as sementes foram pré-umedecidas a 15; 20 e $25 \%$, pelo método do substrato úmido (ROSSETTO; FERNANDEZ; MARCOS FILHO, 1995), e distribuídas 250 sementes $(2,80 \mathrm{~g})$ entre duas camadas de seis folhas de papel germitest umedecidas com 2,5 vezes a massa do papel, sobre tela de alumínio em caixa do tipo gerbox com $40 \mathrm{~mL}$ de água ao fundo e mantidas a $10^{\circ} \mathrm{C}$. Posteriormente, as sementes foram acondicionadas em sacos de papel alumínio, vedados, imersos em água e mantidas sob temperatura de 42 e $45^{\circ} \mathrm{C}$ (GOULART;
TILLMANN, 2007), em aparelho do tipo banho-maria, durante 36 horas, e com base em Larsen et al. (1998) durante 48 horas. Após os períodos de exposição, foram instalados os testes de grau de umidade e de germinação, considerando apenas a primeira contagem. Os resultados foram expressos em porcentagem.

Foi realizado o teste de Lilliefors, visando avaliar a normalidade das variâncias dos erros, (RIBEIRO JUNIOR, 2001). Posteriormente, foram realizadas as análises de variância, com a aplicação do teste F. As médias dos tratamentos foram comparadas pelo teste de Tukey $(p=0,05)$. Também foi realizada a análise de correlação linear simples entre os testes de deterioração controlada e envelhecimento acelerado com os demais.

\section{RESULTADOS E DISCUSSÃO}

Pela Tabela 1, foi verificado que todas as variáveis analisadas atenderam ao pressuposto de normalidade, onde o valor calculado foi menor que a probabilidade de $5 \%$, sendo o valor tabelado igual a 0,157 para peso de mil e de 0,213 para as demais, com exceção da primeira contagem, envelhecimento acelerado sem solução saturada a $45^{\circ} \mathrm{C}$ por 48 horas e deterioração controlada com $15 \%$ a $42{ }^{\circ} \mathrm{C} / 48$ horas e com $25 \%$ a $45^{\circ} \mathrm{C} / 48$ horas. Estas foram normais a $1 \%$ de probabilidade (valor tabelado igual a 0,250), não havendo necessidade da transformação dos dados.

Pela análise de variância somente não foi verificado significância para os dados de grau de umidade, emergência e índice de velocidade de plântulas em areia, deterioração controlada com $25 \%$ de umidade sob $42{ }^{\circ} \mathrm{C}$ durante 36 horas e peso de mil sementes (Tabela 2).

Na Tabela 3 não foi verificado diferença estatística significativa entre os lotes de sementes de nabo forrageiro para o grau de umidade e peso de mil sementes. Este resultado é importante, pois, contribui para que não haja interferência no comportamento das sementes durante a realização dos testes visando a avaliação do potencial fisiológico das mesmas (TEKRONY, 2003).

O teste de germinação classificou os lotes em apenas dois distintos potenciais fisiológicos, sendo os lotes 3 e 4 superiores aos lotes 1 e 2 (Tabela 3). Para Tekrony (2003), este teste não consegue distinguir diferenças sutis na qualidade entre os lotes de sementes, havendo necessidade da utilização de testes de vigor. Além disso, todos os lotes apresentaram valor de germinação acima do padrão de comercialização (60\%) (BRASIL, 2008). Estes resultados reforçam a importância de aplicar os testes de vigor, pois de acordo com Kryzanowski e Vieira (1999) é recomendável a comparação do vigor entre lotes que apresentem semelhança e elevada germinação. 
Tabela 1 - Resultado do teste de normalidade para os dados de quatro lotes de sementes nabo forrageiro, submetidos aos diferentes testes para avaliação da qualidade fisiológica

\begin{tabular}{lccc}
\hline \multicolumn{1}{c}{ Variáveis } & Normalidade & Variáveis & Normalidade \\
\hline Peso de mil sementes & 0,0970 & CS42/48 & 0,1244 \\
Grau de umidade & 0,2003 & CS45/36 & 0,0936 \\
Germinação & 0,1973 & CS45/48 & 0,1177 \\
Primeira contagem & 0,2170 & DC15/42/36 & 0,1187 \\
Comprimento de plântula & 0,1263 & DC15/42/48 & 0,2260 \\
Massa seca de semente & 0,1066 & DC15/45/36 & 0,1109 \\
Condutividade elétrica & 0,1048 & DC15/45/48 & 0,2001 \\
Emergência de areia & 0,1427 & DC20/42/36 & 0,1374 \\
IVE em areia & 0,1471 & DC20/42/48 & 0,1220 \\
Emergência em campo & 0,1752 & DC20/45/36 & 0,1911 \\
IVE em campo & 0,1598 & DC20/45/48 & 0,1466 \\
SS42/36 & 0,1319 & DC25/42/36 & 0,1861 \\
SS42/48 & 0,1675 & DC25/42/48 & 0,1502 \\
SS45/36 & 0,1851 & DC25/45/36 & 0,1291 \\
SS45/48 & 0,2418 & DC25/45/48 & 0,2171 \\
CS42/36 & 0,1163 & & \\
\hline
\end{tabular}

DC- deterioração controlada (sementes pré-umedecidas a $15 ; 20$ e $25 \%$ e mantidas a 42 e $45^{\circ} \mathrm{C}$ durante 36 e 48 horas), SS - envelhecimento acelerado (pelo método sem solução saturada) e CS - (pelo método com solução saturada de $\mathrm{NaCl}$ por 42 e $45^{\circ} \mathrm{C}$ durante 36 e 48 horas)

Tabela 2 - Resumo da análise de variância de quatro lotes de sementes de nabo forrageiro, submetidos aos diferentes testes para avaliação da qualidade fisiológica

\begin{tabular}{|c|c|c|c|c|c|c|c|}
\hline \multirow{2}{*}{ FV } & \multirow{2}{*}{ GL } & \multicolumn{6}{|c|}{ Quadrado Médio } \\
\hline & & GU & $\mathrm{G}$ & $\mathrm{PC}$ & $\mathrm{CP}$ & MSP & $\mathrm{CE}$ \\
\hline Lote & 3 & 0,660 & 262,91 & 541,58 & 1,666 & 49,166 & 240,916 \\
\hline erro & 12 & 0,201 & 4,58 & 28,58 & 0,250 & 9,291 & 10,916 \\
\hline $\mathrm{F}$ & & $3,288^{\mathrm{ns}}$ & $57,63 * *$ & $18,94 * *$ & $6,66 * *$ & $5,29 *$ & $22,069 * *$ \\
\hline \multirow[t]{2}{*}{$\mathrm{CV}(\%)$} & & 6,60 & 2,44 & 7,34 & 14,29 & 10,35 & 3,50 \\
\hline & & EA & IVEA & $\mathrm{EC}$ & IVEC & SS 42/36 & SS 42/48 \\
\hline Lote & 3 & 8,00 & 0,104 & 309,583 & 13,132 & 89,666 & 150,000 \\
\hline erro & 12 & 7,66 & 0,226 & 13,583 & 0,689 & 14,166 & 4,166 \\
\hline $\mathrm{F}$ & & $1,04^{\mathrm{ns}}$ & $0,460^{\text {ns }}$ & $22,791 * *$ & $19,049 * *$ & $6,329 * *$ & $36,00 * *$ \\
\hline \multirow[t]{2}{*}{$\mathrm{CV}(\%)$} & & 2,93 & 3,10 & 4,0 & 8,08 & 5,17 & 2,47 \\
\hline & & SS $45 / 36$ & SS 45/48 & CS $42 / 36$ & CS 42/48 & CS $45 / 36$ & CS $45 / 48$ \\
\hline Lote & 3 & 945,661 & 872,666 & 386,00 & 327,333 & 220,916 & 491,333 \\
\hline erro & 12 & 8,833 & 6,833 & 12,833 & 7,166 & 23,250 & 12,50 \\
\hline $\mathrm{F}$ & & $107,057 * *$ & $127,707 * *$ & $30,078 * *$ & $45,674 * *$ & $9,502 * *$ & $39,307 * *$ \\
\hline \multirow[t]{2}{*}{$\mathrm{CV}(\%)$} & & 5,06 & 4,71 & 4,84 & 3,24 & 6,46 & 4,48 \\
\hline & & D15/42/36 & $\mathrm{D} 15 / 42 / 48$ & D15/45/36 & D15/45/48 & D20/42/36 & D20/42/48 \\
\hline Lote & 3 & 556,666 & 192,250 & 929,586 & 384,916 & 655,00 & 236,250 \\
\hline erro & 12 & 34,50 & 9,250 & 27,25 & 36,916 & 8,833 & 7,083 \\
\hline $\mathrm{F}$ & & $16,135^{* *}$ & $20,784 * *$ & $33,498 * *$ & $10,427 * *$ & $74,151 * *$ & $33,353 * *$ \\
\hline $\mathrm{CV}(\%)$ & & 7,78 & 3,96 & 6,90 & 9,02 & 3,70 & 3,43 \\
\hline
\end{tabular}


Continuação Tabela 2

\begin{tabular}{|c|c|c|c|c|c|c|c|}
\hline & & D20/45/36 & D20/45/48 & D25/42/36 & D25/42/48 & D25/45/36 & D25/45/48 \\
\hline Lote & 3 & 944,250 & 332,33 & 16,250 & 460,916 & 495,58 & 295,583 \\
\hline erro & 12 & 7,583 & 16,166 & 19,750 & 21,750 & 19,91 & 23,416 \\
\hline $\mathrm{F}$ & & $124,516^{* *}$ & $20,557 * *$ & $0,823^{\mathrm{ns}}$ & $21,192 * *$ & $24,883 * *$ & $12,623^{* *}$ \\
\hline \multirow[t]{2}{*}{$\mathrm{CV}(\%)$} & & 3,54 & 5,64 & 5,46 & 6,87 & 5,54 & 6,46 \\
\hline & & P1000 & & & & & \\
\hline Lote & 3 & 0,153 & & & & & \\
\hline erro & 28 & 0,072 & & & & & \\
\hline $\mathrm{F}$ & & $2,112^{\mathrm{ns}}$ & & & & & \\
\hline $\mathrm{CV}(\%)$ & & 2,58 & & & & & \\
\hline
\end{tabular}

G- germinação; PC- primeira contagem; CP- comprimento de plântulas; MSP- massa seca de plântulas; CE- condutividade elétrica; EA emergência em areia; IVEA - índice de velocidade de emergência; EC- emergência em campo; IVEC- índice de velocidade de emergência em campo, SS - envelhecimento acelerado pelo método sem solução saturada; CS - envelhecimento pelo método com solução saturada de NaCl (por 42 e $45^{\circ} \mathrm{C}$ durante 36 e 48 horas), D- deterioração controlada (sementes pré-umedecidas a $15 ; 20$ e $25 \%$ e mantidas a 42 e $45{ }^{\circ} \mathrm{C}$ durante 36 e 48 horas) e P1000- peso de mil sementes. ${ }^{* *}$ significativo em nível de $1 \%$; $*$ significativo em nível de $5 \%$ e ${ }^{\mathrm{n}}$ não significativo pelo teste $\mathrm{F}$

Tabela 3 - Valores médios de peso de mil sementes (g); grau de umidade (\%); plântulas normais na primeira contagem (\%); germinação (\%); comprimento de plântula (cm plântula $\left.{ }^{-1}\right)$ e massa seca de plântula (mg plântula $\left.{ }^{-1}\right)$, de quatro lotes de sementes de nabo forrageiro

\begin{tabular}{lcccccc}
\hline Lotes & Peso de Mil & Grau de Umidade & Germinação & Primeira Contagem & Comprimento de Plântula & Massa Seca de Plântula \\
\hline 1 & $10,31 \mathrm{a}^{1}$ & $6,9 \mathrm{a}$ & $82 \mathrm{~b}$ & $63 \mathrm{c}$ & $3,25 \mathrm{ab}$ & $14,75 \mathrm{ab}$ \\
2 & $10,78 \mathrm{a}$ & $7,3 \mathrm{a}$ & $80 \mathrm{~b}$ & $65 \mathrm{c}$ & $2,75 \mathrm{~b}$ & $11,25 \mathrm{~b}$ \\
3 & $11,02 \mathrm{a}$ & $6,4 \mathrm{a}$ & $91 \mathrm{a}$ & $74 \mathrm{~b}$ & $3,75 \mathrm{ab}$ & $19,00 \mathrm{a}$ \\
4 & $11,34 \mathrm{a}$ & $6,8 \mathrm{a}$ & $97 \mathrm{a}$ & $88 \mathrm{a}$ & $4,25 \mathrm{a}$ & $18,00 \mathrm{a}$ \\
\hline
\end{tabular}

${ }^{1}$ Médias seguidas da mesma letra, na coluna, não diferem entre si pelo teste de Tukey em nível de 5\% de significância

Quando o vigor foi avaliado pelo teste de primeira contagem, este classificou os lotes em três distintos níveis, sendo verificada a superioridade do lote 4, o nível intermediário do lote 3 e a inferioridade dos lotes 1 e 2 (Tabela 3). Assim, apesar do teste de primeira contagem ser conduzido juntamente com o teste de germinação, este conseguiu classificar os lotes em mais níveis de vigor, pois a velocidade de germinação é reduzida com o avanço do processo de deterioração natural das sementes (BARROS et al., 2002). Em sementes de brássicas como repolho, couve-brocolis e couve, Costa, Trzeciak e Villela (2008) também observaram que o teste de primeira contagem apresentou sensibilidade em detectar pequenas diferenças no potencial fisiológico, classificando os lotes destas três espécies em quatro níveis de vigor. No entanto, em nabo forrageiro, Nery, Carvalho e Guimarães (2009) verificaram que este teste classificou os lotes somente em dois níveis, semelhantemente ao teste de germinação.

$\mathrm{O}$ teste de comprimento de plântula classificou o lote 4 como de nível superior, os lotes 1 e 3 como de nível intermediários e o lote 2 como de nível inferior de vigor
(Tabela 3). Já, o teste de massa seca de plântula classificou os lotes 3 e 4 como de nível superior, o lote 1 como intermediário e o lote 2 como de nível inferior (Tabela 3). Assim estes testes classificaram o lote 4 com vigor superior e o lote 2 com vigor inferior. De acordo com Henning et al. (2010), sementes mais vigorosas possuem elevada capacidade de mobilização de reservas na germinação, com maior translocação destas para o eixo embrionário, resultando no aumento da massa seca e comprimento da plântula em relação às sementes menos vigorosas. Além disso, em sementes de rúcula, Goulart e Tillmann (2007) verificaram que o teste de comprimento de plântulas separou os lotes em três níveis de vigor.

Pelo teste de condutividade elétrica, foi possível classificar os lotes em três níveis de vigor, sendo o lote 4 com vigor superior, os lotes 2 e 3 com vigor intermediário e o lote 1 com vigor inferior (Tabela 4 ). Em rúcula, Torres e Pereira (2010) também observaram a separação dos lotes em três níveis de vigor, após terem sido utilizadas 25 sementes em $50 \mathrm{~mL}$ sob $20^{\circ} \mathrm{C}$ durante 24 horas. No entanto, Nery, Carvalho e Guimarães (2009), para sementes de nabo forrageiro, observaram que a combinação de 25 sementes 
Tabela 4 - Valores médios de condutividade elétrica $\left(\mu \mathrm{S} \mathrm{m}^{-1} \mathrm{~g}^{-1}\right.$ ), emergência em areia e em campo (\%); IVE em areia e em campo, de quatro lotes de sementes de nabo forrageiro

\begin{tabular}{|c|c|c|c|c|c|}
\hline \multirow{2}{*}{ Lotes } & \multirow{2}{*}{ Condutividade } & \multicolumn{2}{|c|}{ - } & \multicolumn{2}{|c|}{-------------'Campo--------------- } \\
\hline & & Emergência & IVE & Emergência & IVE \\
\hline 1 & $103,75 \mathrm{a}^{1}$ & $96 \mathrm{a}$ & $15,46 \mathrm{a}$ & $74 \mathrm{c}$ & $8,49 \mathrm{~b}$ \\
\hline 2 & $94,23 \mathrm{~b}$ & $95 \mathrm{a}$ & $15,31 \mathrm{a}$ & $78 \mathrm{bc}$ & $9,63 \mathrm{~b}$ \\
\hline 3 & $94,74 \mathrm{~b}$ & $93 \mathrm{a}$ & $15,15 \mathrm{a}$ & $82 \mathrm{~b}$ & $10,81 \mathrm{~b}$ \\
\hline 4 & $84,83 \mathrm{c}$ & $96 \mathrm{a}$ & $15,50 \mathrm{a}$ & $94 \mathrm{a}$ & $12,78 \mathrm{a}$ \\
\hline
\end{tabular}

${ }^{1}$ Médias seguidas da mesma letra, na coluna, não diferem entre si pelo teste de Tukey em nível de 5\% de significância

em $50 \mathrm{~mL}$ de água sob $25^{\circ} \mathrm{C}$ durante 6 horas foi mais eficiente, classificando os lotes em quatro níveis de vigor.

$\mathrm{Na}$ Tabela 4, pelos testes de emergência em areia e de índice de velocidade de emergência de plântulas (IVE) em areia não foi possível classificar os lotes em distintos níveis de vigor. Esses resultados estão de acordo com os obtidos por Costa, Trzeciak e Villela (2008), os quais não verificaram diferenciação dos lotes em níveis de vigor de sementes de couve pelo teste de índice de velocidade de emergência de plântulas, assim como, de sementes de repolho pelo teste de emergência de plântulas. $O$ teste de índice de velocidade de emergência de plântulas em campo classificou o lote 4 como de nível superior, e os de mais como de nível inferior (Tabela 4). No entanto, pelo teste de emergência de plântulas em campo, foi possível separar os lotes em quatro níveis de vigor, indicando o lote 4 como superior, o lote 1 como inferior e os lotes 2 e 3 como intermediários, destacando-se entre os dois o lote 3 (Tabela 4). Em sementes de canola Ávila et al. (2005) observaram a distinção dos lotes em quatro níveis de vigor pelo teste de emergência de plântulas em campo.

O teste de envelhecimento sem solução saturada de $\mathrm{NaCl}$ sob temperatura de $45^{\circ} \mathrm{C}$ durante 36 horas, similarmente classificou os lotes em três níveis de vigor (Tabela 5), o lote 4 como de nível superior, o lote 3 como de nível intermediário e os lotes 1 e 2 como de nível inferior. Este resultado foi semelhante ao obtido pelo teste de primeira contagem (Tabela 3 ).

Já o teste de envelhecimento acelerado com solução saturada de $\mathrm{NaCl}$ sob temperatura de $45^{\circ} \mathrm{C}$ durante 36 horas apresentou maior sensibilidade em detectar diferenças entre os lotes de sementes de nabo forrageiro, classificando os lotes em quatro níveis de vigor, indicando a superioridade do lote 4, a inferioridade do lote 1, e o nível intermediário dos lotes 2 e 3, com destaque para o lote 3 (Tabela 5). Assim, estes resultados permitiram verificar a maior eficiência deste teste ao utilizar solução saturada, empregando esta combinação de tempo e temperatura, em relação ao teste de germinação (Tabela 3), que apenas separou os lotes em dois potenciais fisiológicos distintos. Além disso, este resultado foi semelhante ao obtido pelo teste de emergência de plântulas em campo (Tabela 4). Fessel et al. (2005) enfatizam a utilização da solução saturada para sementes pequenas em relação ao procedimento tradicional, por provocar menor taxa de deterioração e, consequentemente proporcionar resultados menos drásticos e mais uniformes. Já em rúcula, Ramos et al. (2004) verificaram que a utilização de solução saturada sob $45{ }^{\circ} \mathrm{C}$ durante 48 horas classificou os lotes em quatro níveis de vigor. E, em nabo forrageiro, Nery, Carvalho e Guimarães (2009) verificaram distinção dos lotes de nabo forrageiro em três níveis de qualidade sob temperatura de $41{ }^{\circ} \mathrm{C}$ durante 72 horas pelo método com solução saturada. Assim, neste trabalho, a utilização de temperatura mais elevada $\left(45^{\circ} \mathrm{C}\right)$ pode ter proporcionado intensificação do estresse ocasionando maior distinção do vigor entre os lotes de sementes, como comentando por Kikuti e Marcos Filho (2008), e o menor período de exposição (36 horas) ter sido suficiente para o ranqueamento de lotes com maior potencial fisiológico como comentado por Lima e Marcos Filho (2011).

Outro aspecto a abordar quanto ao teste de envelhecimento acelerado está relacionado à avaliação do teor de água após o procedimento de exposição ao estresse térmico. Foi observado que a utilização de solução saturada de $\mathrm{NaCl}$ favoreceu a obtenção de menores valores de teores de água das sementes e variações menos acentuadas entre lotes, permanecendo no limite tolerável de $2 \%$ (Tabela 5). Assim ao utilizar solução saturada de $\mathrm{NaCl}$ ocorre a diminuição da disponibilidade de água, reduzindo a velocidade de absorção da água e, consequentemente as sementes atingem menor teor de água, como comentado por Ramos et al. (2004). Estes resultados relacionados à menor variação do teor de água após este procedimento também foram observados na avaliação de outras espécies de brássicas, como couve e repolho (COSTA; TRZECIAK; VILLELA, 2008; KOMBA; BRANTON; HAMPTON, 2006). 
Tabela 5 - Valores médios (\%), de plântulas normais na primeira contagem de germinação e dos teores de água, de quatro lotes de sementes de nabo forrageiro após o teste de envelhecimento acelerado com ou sem solução saturada de $\mathrm{NaCl}$, sob temperatura de 42 e $45^{\circ} \mathrm{C}$, durante 36 e 48 horas

\begin{tabular}{|c|c|c|c|c|c|}
\hline \multirow{2}{*}{ Tratamentos } & \multirow{2}{*}{ Lotes } & \multicolumn{2}{|c|}{$42^{\circ} \mathrm{C}$} & \multicolumn{2}{|c|}{$45^{\circ} \mathrm{C}$} \\
\hline & & $36 \mathrm{~h}$ & $48 \mathrm{~h}$ & $36 \mathrm{~h}$ & $48 \mathrm{hs}$ \\
\hline & & \multicolumn{4}{|c|}{ Plântulas normais (\%) } \\
\hline & 1 & $68 b^{1}$ & $86 \mathrm{a}$ & $45 \mathrm{c}$ & $44 \mathrm{~b}$ \\
\hline & 2 & $70 a b$ & $76 \mathrm{~b}$ & $50 \mathrm{c}$ & $42 \mathrm{~b}$ \\
\hline & 3 & $77 \mathrm{a}$ & $79 \mathrm{~b}$ & $62 \mathrm{~b}$ & $70 \mathrm{a}$ \\
\hline & 4 & $77 \mathrm{a}$ & $90 \mathrm{a}$ & $79 \mathrm{a}$ & $67 \mathrm{a}$ \\
\hline \multirow[t]{10}{*}{ Sem $\mathrm{NaCl}$} & & \multicolumn{4}{|c|}{ Teores de água (\%) } \\
\hline & 1 & 27,1 & 30,3 & 26,6 & 25,5 \\
\hline & 2 & 25,3 & 30,7 & 28,1 & 30,6 \\
\hline & 3 & 23,1 & 35,9 & 21,8 & 33,8 \\
\hline & 4 & 28,4 & 35,7 & 25,9 & 31,4 \\
\hline & & \multicolumn{4}{|c|}{ Plântulas normais (\%) } \\
\hline & 1 & $63 \mathrm{~b}$ & $78 \mathrm{~b}$ & $66 \mathrm{c}$ & $66 \mathrm{c}$ \\
\hline & 2 & $70 \mathrm{~b}$ & $73 \mathrm{~b}$ & $72 \mathrm{bc}$ & $74 \mathrm{~b}$ \\
\hline & 3 & $79 a$ & $88 \mathrm{a}$ & $78 \mathrm{ab}$ & $86 a$ \\
\hline & 4 & $85 \mathrm{a}$ & $92 \mathrm{a}$ & $83 \mathrm{a}$ & $91 \mathrm{a}$ \\
\hline \multirow[t]{5}{*}{ Com $\mathrm{NaCl}$} & & \multicolumn{4}{|c|}{ Teores de água (\%) } \\
\hline & 1 & 9,2 & 8,7 & 8,9 & 9,5 \\
\hline & 2 & 9,7 & 9,3 & 8,9 & 11,0 \\
\hline & 3 & 9,8 & 9,0 & 9,3 & 9,1 \\
\hline & 4 & 8,3 & 11,1 & 10,8 & 9,9 \\
\hline
\end{tabular}

${ }^{1}$ Médias seguidas da mesma letra, na coluna, não diferem entre si pelo teste de Tukey em nível de 5\% de significância

O teste de deterioração controlada com sementes pré-umedecidas a $15 \%$ sob $42{ }^{\circ} \mathrm{C}$ durante 48 horas classificou o lote 4 como de nível superior, o lote 3 como de nível intermediário e, os lotes 1 e 2, como de nível inferior (Tabela 6). Este resultado foi similar ao obtido pelo teste de primeira contagem (Tabela 3 ) e pelo teste de envelhecimento acelerado sem solução saturada sob $42^{\circ} \mathrm{C}$ durante 36 horas (Tabela 5).

No entanto, o teste de deterioração controlada empregando sementes pré-umedecidas a $20 \%$ sob $45{ }^{\circ} \mathrm{C}$ durante 36 horas e sementes pré-umedecidas a $25 \%$ sob $45^{\circ} \mathrm{C}$ durante 48 horas separam os lotes em quatro níveis de vigor, indicando o lote 4 como superior, o lote 1 como inferior e os lotes 2 e 3 como intermediários, com destaque para a superioridade do lote 3 (Tabela 6). Estes resultados foram semelhantes aos obtidos pelo teste de emergência de plântulas em campo (Tabela 4) e pelo teste de envelhecimento acelerado com solução saturada de $\mathrm{NaCl}$ sob $45^{\circ} \mathrm{C}$ por 36 horas (Tabela 5), reforçando a maior eficiência destes testes na distinção entre os lotes quanto ao nível de vigor. De acordo com Mendonça, Ramos e Fessel (2003) é importante a utilização de vários testes de vigor para caracterizar lotes com viabilidade próxima.

Rossetto e Marcos Filho (1995) e Marcos Filho, Novembre e Chamma (2001) também relataram que o teste de deterioração controlada foi tão eficiente quanto o de envelhecimento acelerado para classificação do potencial fisiológico das sementes de soja. No entanto, de acordo com Lima e Marcos Filho (2011), este teste requer determinado período de tempo para realizar o pré-umedecimento das sementes visando o ajuste do grau de umidade, sendo esta etapa trabalhosa, o que leva a necessidade do envolvimento de profissionais habilitados para a sua execução. Além disso, para outras brássicas, como brócolis (MENDONÇA; RAMOS; FESSEL, 2005) e repolho (DEMIR et al., 2008; MATTHEWS et al., 2009), o teste de deterioração controlada foi considerado eficiente 
Tabela 6 - Valore médios (\%) de plântulas normais na primeira contagem de germinação e dos teores de água, de quatro lotes de sementes de nabo forrageiro pré-umedecidas a $15 ; 20$ e $25 \%$ e mantidas sob temperatura de 42 e $45^{\circ} \mathrm{C}$, durante 36 e 48 horas

\begin{tabular}{|c|c|c|c|c|c|}
\hline \multirow{2}{*}{ Tratamentos } & \multirow{2}{*}{ Lotes } & \multicolumn{2}{|c|}{$42^{\circ} \mathrm{C}$} & \multicolumn{2}{|c|}{$45^{\circ} \mathrm{C}$} \\
\hline & & $36 h$ & $48 \mathrm{~h}$ & $36 \mathrm{~h}$ & $48 \mathrm{~h}$ \\
\hline \multirow[t]{5}{*}{ Teor de água $(\%)$} & & \multicolumn{4}{|c|}{ Plântulas normais (\%) } \\
\hline & 1 & $59 b^{1}$ & $71 \mathrm{c}$ & $58 \mathrm{c}$ & $57 \mathrm{c}$ \\
\hline & 2 & $87 \mathrm{a}$ & $72 \mathrm{c}$ & $71 \mathrm{~b}$ & $72 \mathrm{ab}$ \\
\hline & 3 & $79 \mathrm{a}$ & $79 \mathrm{~b}$ & $86 \mathrm{a}$ & $62 \mathrm{bc}$ \\
\hline & 4 & $78 \mathrm{a}$ & $86 a$ & $92 \mathrm{a}$ & $79 a$ \\
\hline \multirow[t]{10}{*}{15} & & \multicolumn{4}{|c|}{ Teores de água (\%) } \\
\hline & 1 & 16,3 & 13,7 & 14,3 & 14,1 \\
\hline & 2 & 15,0 & 14,6 & 16,4 & 15,1 \\
\hline & 3 & 15,5 & 16,8 & 15,2 & 15,2 \\
\hline & 4 & 15,9 & 14,2 & 15,2 & 15,0 \\
\hline & & \multicolumn{4}{|c|}{ Plântulas normais (\%) } \\
\hline & 1 & $63 \mathrm{c}$ & $69 \mathrm{c}$ & $56 \mathrm{c}$ & $58 \mathrm{~b}$ \\
\hline & 2 & $80 \mathrm{~b}$ & $76 b$ & $81 \mathrm{~b}$ & $76 \mathrm{a}$ \\
\hline & 3 & $85 \mathrm{~b}$ & $79 \mathrm{~b}$ & $85 \mathrm{ab}$ & $73 \mathrm{a}$ \\
\hline & 4 & $94 \mathrm{a}$ & $88 \mathrm{a}$ & $90 \mathrm{a}$ & $79 \mathrm{a}$ \\
\hline \multirow[t]{10}{*}{20} & \multicolumn{5}{|c|}{ Teores de água (\%) } \\
\hline & 1 & 20,8 & 20,2 & 19,5 & 20,0 \\
\hline & 2 & 20,1 & 19,9 & 20,0 & 20,1 \\
\hline & 3 & 20,1 & 19,4 & 21,0 & 20,3 \\
\hline & 4 & 20,0 & 20,3 & 19,1 & 20,7 \\
\hline & & \multicolumn{4}{|c|}{ Plântulas normais (\%) } \\
\hline & 1 & $83 \mathrm{a}$ & $57 \mathrm{c}$ & $66 \mathrm{c}$ & $65 \mathrm{c}$ \\
\hline & 2 & $83 \mathrm{a}$ & $71 \mathrm{~b}$ & $79 \mathrm{~b}$ & $72 \mathrm{bc}$ \\
\hline & 3 & $79 \mathrm{a}$ & $63 \mathrm{bc}$ & $89 \mathrm{a}$ & $79 a b$ \\
\hline & 4 & $82 \mathrm{a}$ & $82 \mathrm{a}$ & $89 \mathrm{a}$ & $85 \mathrm{a}$ \\
\hline \multirow[t]{5}{*}{25} & \multicolumn{5}{|c|}{ Teores de água (\%) } \\
\hline & 1 & 24,3 & 24,4 & 24,7 & 25,0 \\
\hline & 2 & 23,2 & 25,3 & 23,5 & 24,9 \\
\hline & 3 & 24,6 & 25,0 & 24,1 & 24,4 \\
\hline & 4 & 24,9 & 24,5 & 24,9 & 24,7 \\
\hline
\end{tabular}

${ }^{1}$ Médias seguidas da mesma letra, na coluna, não diferem entre si pelo teste de Tukey em nível de 5\% de significância

quando se empregou sementes pré-umedecidas a $20 \%$ sob $45^{\circ} \mathrm{C}$ durante 24 horas na separação dos lotes em quatro níveis de vigor.

Na Tabela 6 foi observado que as sementes após a exposição ao estresse térmico proporcionado pelo teste de deterioração controlada apresentaram pequena variação dos teores iniciais de água. Tekrony (2003) relata que a precisão do teor de água das sementes nos testes de deterioração controlada é a principal premissa para a eficácia deste teste, pois variação de $1 \%$ no teor de água das sementes pode refletir em mudanças diretas no processo germinativo após a deterioração controlada, principalmente para lotes de médio e baixo vigor, proporcionando assim resultados inconsistentes. 
Pode-se observar na Tabela 7, correlação significativa entre os testes de envelhecimento acelerado com solução saturada sob $45^{\circ} \mathrm{C}$ durante 36 e 48 horas e o teste de emergência em campo $\left(r=0,57^{*}\right.$ e $r=0,56 *$ ) (Tabela 5). Em couve, Komba, Brunton e Hampton (2006) verificaram correlação entre o teste de envelhecimento acelerado sob $41^{\circ} \mathrm{C}$ durante 48 horas e o teste de emergência em campo. No entanto, também foi verificada correlação significativa entre o teste de envelhecimento acelerado sem solução saturada sob $45^{\circ} \mathrm{C}$, durante 36 horas com os testes de emergência em areia $\left(\mathrm{r}=-0,77^{*} *\right)$ e o teste de índice de velocidade de emergência em areia $\left(\mathrm{r}=-0,73^{* *}\right)$, sendo que este teste de envelhecimento apenas classificou os lotes em três níveis de vigor (Tabela 5).

Quanto ao teste de deterioração controlada, foi constatada correlação significativa entre este teste conduzido com sementes pré-umedecidas $20 \%$, sob $45^{\circ} \mathrm{C}$ durante 36 horas com o teste de emergência em campo $\left(\mathrm{r}=0,73^{*}\right)$; assim como entre o teste com sementes pré-umedecidas a $25 \%$, sob $45^{\circ} \mathrm{C}$ durante 48 horas com o teste de emergência em campo $\left(r=0,74^{*}\right)$ (Tabela 8). Estes resultados confirmam os obtidos na classificação do vigor através da análise pelo teste de média (Tabela 4). Em sementes de canola, Larsen et al. (1998) também observaram correlação entre o teste de deterioração controlada com sementes pré-umedecidas a $20 \%$ sob $45^{\circ} \mathrm{C}$ durante 24 horas e o teste de emergência em campo.

Há inúmeros trabalhos na literatura recomendando a realização do teste de correlação entre os testes de laboratório para avaliação do potencial fisiológico dos lotes de sementes com o teste de emergência de plântulas em campo. No entanto, Marcos Filho (1999) ressalta a importância de não se utilizar exclusivamente a correlação para avaliar a eficiência dos testes de vigor, devendo ser interpretados em conjunto com o teste de média. Outro aspecto observado nas Tabelas 7 e 8, foi o baixo coeficiente obtido nos testes de correlação. Demir et al. (2008) também verificaram baixos coeficientes de correlação entre os testes de laboratório apenas ao utilizar um conjunto de lotes de sementes de repolho, que apresentava elevado potencial fisiológico. Assim, demonstrando que o potencial inicial do conjunto de lotes pode interferir nos resultados avaliados.

Tabela 7 - Coeficientes de correlação de Person (r) entre os resultados do teste de envelhecimento acelerado com ou sem solução saturada de $\mathrm{NaCl}$ (por 42 e $45^{\circ} \mathrm{C}$ durante 36 e 48 horas) com diferentes testes de qualidade, de quatro lotes de sementes de nabo forrageiro

Envelhecimento acelerado

\begin{tabular}{|c|c|c|c|c|c|c|c|c|}
\hline & \multicolumn{4}{|c|}{ 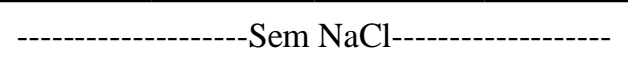 } & \multicolumn{4}{|c|}{ 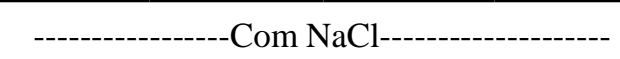 } \\
\hline & $42 / 36$ & $42 / 48$ & $45 / 36$ & $45 / 48$ & $42 / 36$ & $42 / 48$ & $45 / 36$ & $45 / 48$ \\
\hline $\mathrm{DC} 15 / 42 / 36$ & $0,34^{\mathrm{ns}}$ & $-0,03^{\text {ns }}$ & $-0,49 *$ & $-0,21^{\mathrm{ns}}$ & $-0,10^{\mathrm{ns}}$ & $0,19^{\text {ns }}$ & $0,39^{\text {ns }}$ & $-0,43^{*}$ \\
\hline DC15/42/48 & $-0,49 *$ & $-0,54^{*}$ & $0,06^{\mathrm{ns}}$ & $-0,26^{\mathrm{ns}}$ & $-0,27^{\mathrm{ns}}$ & $0,10^{\text {ns }}$ & $0,05^{\mathrm{ns}}$ & $-0,05^{\mathrm{ns}}$ \\
\hline DC15/45/36 & $0,40^{\text {ns }}$ & $0,15^{\mathrm{ns}}$ & $-0,40^{\text {ns }}$ & $-0,05^{\mathrm{ns}}$ & $0,14^{\mathrm{ns}}$ & $0,22^{\mathrm{ns}}$ & $0,33^{\text {ns }}$ & $-0,34^{\mathrm{ns}}$ \\
\hline DC15/45/48 & $0,41^{\mathrm{ns}}$ & $-0,17^{\mathrm{ns}}$ & $-0,11^{\mathrm{ns}}$ & $0,14^{\mathrm{ns}}$ & $-0,65^{*}$ & $-0,33^{\text {ns }}$ & $-0,05^{\mathrm{ns}}$ & $-0,11^{\mathrm{ns}}$ \\
\hline G & $0,30^{\mathrm{ns}}$ & $0,56^{*}$ & $0,40^{*}$ & $-0,14^{\mathrm{ns}}$ & $-0,24^{\mathrm{ns}}$ & $-0,28^{\mathrm{ns}}$ & $-0,17^{\mathrm{ns}}$ & $0,11^{\mathrm{ns}}$ \\
\hline $\mathrm{PC}$ & $0,12^{\mathrm{ns}}$ & $-0,04^{\mathrm{ns}}$ & $-0,06^{\mathrm{ns}}$ & $-0,36^{\mathrm{ns}}$ & $0,21^{\mathrm{ns}}$ & $-0,49 *$ & $-0,44^{*}$ & $-0,28^{\text {ns }}$ \\
\hline $\mathrm{CP}$ & $0,18^{\mathrm{ns}}$ & $-0,31^{\mathrm{ns}}$ & $0,11^{\mathrm{ns}}$ & $0,38^{\mathrm{ns}}$ & $0,21^{\mathrm{ns}}$ & $-0,53^{*}$ & $-0,15^{\mathrm{ns}}$ & $0,15^{\mathrm{ns}}$ \\
\hline MSP & $-0,19^{\text {ns }}$ & $-0,35^{\mathrm{ns}}$ & $0,16^{\text {ns }}$ & $0,76 * *$ & $0,41^{\mathrm{ns}}$ & $-0,25^{\mathrm{ns}}$ & $-0,46^{*}$ & $0,47 *$ \\
\hline $\mathrm{CE}$ & $-0,28^{\mathrm{ns}}$ & $0,02^{\mathrm{ns}}$ & $-0,13^{\text {ns }}$ & $-0,42 *$ & $0,16^{\mathrm{ns}}$ & $0,45^{*}$ & $0,20^{\mathrm{ns}}$ & $-0,26^{\mathrm{ns}}$ \\
\hline A & $-0,03^{\text {ns }}$ & $-0,12^{\mathrm{ns}}$ & $-0,77^{* *}$ & $0,44 *$ & $0,18^{\mathrm{ns}}$ & $0,25^{\mathrm{ns}}$ & $-0,26^{\mathrm{ns}}$ & $0,32^{\mathrm{ns}}$ \\
\hline IVE & $0,18^{\mathrm{ns}}$ & $-0,14^{\mathrm{ns}}$ & $-0,73^{* *}$ & $0,34^{\mathrm{ns}}$ & $0,21^{\mathrm{ns}}$ & $0,11^{\mathrm{ns}}$ & $-0,46^{*}$ & $0,47 *$ \\
\hline EC & $-0,46^{*}$ & $-0,14^{\mathrm{ns}}$ & $-0,17^{\mathrm{ns}}$ & $0,34^{\mathrm{ns}}$ & $0,28^{\mathrm{ns}}$ & $-0,16^{\mathrm{ns}}$ & $0,57^{*}$ & $0,56^{*}$ \\
\hline IVEC & $-0,54^{*}$ & $0,03^{\text {ns }}$ & $-0,17^{\mathrm{ns}}$ & $0,29^{\mathrm{ns}}$ & $0,32^{\mathrm{ns}}$ & $0,43^{*}$ & $-0,13^{\text {ns }}$ & $0,16^{\mathrm{ns}}$ \\
\hline
\end{tabular}

DC- deterioração controlada (sementes pré-umedecidas a $15 \%$, mantidas a 42 e $45^{\circ} \mathrm{C}$ durante 36 e 48 horas), G- germinação; PC- primeira contagem; CP- comprimento de plântulas; MSP- massa seca de plântulas; CE- condutividade elétrica A - emergência em areia; IVE - índice de velocidade de emergência; EC- emergência em campo; IVEC-índice de velocidade de emergência em campo** significativo em nível de $1 \%$; * significativo em nível de $5 \%$ e ns não significativo pelo teste $\mathrm{t}$ 
Tabela 8 - Coeficientes de correlação de Person (r) entre os resultados do teste de deterioração controlada (sementes pré-umedecidas a 20 e $25 \%$, mantidas a 42 e $45^{\circ} \mathrm{C}$ durante 36 e 48 horas) com diferentes testes de qualidade, de quatro lotes de sementes de nabo forrageiro

\begin{tabular}{|c|c|c|c|c|c|c|c|c|}
\hline \multicolumn{9}{|c|}{ Deterioração controlada } \\
\hline & \multicolumn{4}{|c|}{--------------------------20\%"----------------------- } & \multicolumn{4}{|c|}{-----------------------25\%------------------------ } \\
\hline & $42 / 36$ & $42 / 48$ & $45 / 36$ & $45 / 48$ & $42 / 36$ & $42 / 48$ & $45 / 36$ & $45 / 48$ \\
\hline $\mathrm{SS} 42 / 36$ & $-0,07^{\mathrm{ns}}$ & $0,19^{\text {ns }}$ & $0,20^{\mathrm{ns}}$ & $0,39^{\text {ns }}$ & $0,09^{\text {ns }}$ & $-0,49 *$ & $0,50 *$ & $0,21^{\mathrm{ns}}$ \\
\hline $\mathrm{SS} 42 / 48$ & $0,37^{\mathrm{ns}}$ & $0,53 *$ & $0,04^{\mathrm{ns}}$ & $0,09^{\text {ns }}$ & $0,43^{*}$ & $-0,21^{\mathrm{ns}}$ & $0,27^{\mathrm{ns}}$ & $0,06^{\mathrm{ns}}$ \\
\hline $\mathrm{SS} 45 / 36$ & $-0,08^{\mathrm{ns}}$ & $-0,17^{\mathrm{ns}}$ & $0,15^{\mathrm{ns}}$ & $-0,46^{*}$ & $-0,04^{\mathrm{ns}}$ & $0,13^{\mathrm{ns}}$ & $0,39^{\mathrm{ns}}$ & $-0,27^{\mathrm{ns}}$ \\
\hline SS45/48 & $0,18^{\mathrm{ns}}$ & $-0,27^{\mathrm{ns}}$ & $-0,54 *$ & $-0,09^{\text {ns }}$ & $0,34^{\mathrm{ns}}$ & $-0,43^{*}$ & $-0,10^{\mathrm{ns}}$ & $-0,05^{\mathrm{ns}}$ \\
\hline CS42/36 & $0,31^{\mathrm{ns}}$ & $-0,14^{\mathrm{ns}}$ & $-0,10^{\mathrm{ns}}$ & $-0,27^{\mathrm{ns}}$ & $-0,08^{\mathrm{ns}}$ & $0,05^{\mathrm{ns}}$ & $-0,10^{\mathrm{ns}}$ & $-0,61 *$ \\
\hline CS42/48 & $0,57 *$ & $0,17^{\mathrm{ns}}$ & $-0,35^{\mathrm{ns}}$ & $-0,17^{\mathrm{ns}}$ & $0,04^{\mathrm{ns}}$ & $0,10^{\mathrm{ns}}$ & $-0,66^{*}$ & $-0,07^{\mathrm{ns}}$ \\
\hline CS45/36 & $0,41 *$ & $0,39^{\mathrm{ns}}$ & $0,03^{\mathrm{ns}}$ & $0,33^{\mathrm{ns}}$ & $0,56^{*}$ & $0,14^{\mathrm{ns}}$ & $-0,17^{\mathrm{ns}}$ & $0,30^{\mathrm{ns}}$ \\
\hline CS45/48 & $0,30^{\mathrm{ns}}$ & $0,08^{\mathrm{ns}}$ & $0,15^{\mathrm{ns}}$ & $0,29^{\mathrm{ns}}$ & $0,14^{\mathrm{ns}}$ & $0,62 * *$ & $0,12^{\mathrm{ns}}$ & $0,09^{\mathrm{ns}}$ \\
\hline G & $-0,01^{\mathrm{ns}}$ & $0,08^{\mathrm{ns}}$ & $0,08^{\mathrm{ns}}$ & $-0,07^{\mathrm{ns}}$ & $0,39^{\mathrm{ns}}$ & $-0,31^{\mathrm{ns}}$ & $0,65^{*}$ & $0,06^{\mathrm{ns}}$ \\
\hline PC & $-0,20^{\mathrm{ns}}$ & $-0,37^{\mathrm{ns}}$ & $-0,16^{\mathrm{ns}}$ & $0,09^{\mathrm{ns}}$ & $-0,18^{\mathrm{ns}}$ & $-0,07^{\mathrm{ns}}$ & $0,23^{\mathrm{ns}}$ & $-0,47 *$ \\
\hline $\mathrm{CP}$ & $-0,08^{\mathrm{ns}}$ & $-0,52 *$ & $-0,03^{\mathrm{ns}}$ & $0,29^{\text {ns }}$ & $-0,12^{\mathrm{ns}}$ & $-0,52 *$ & $0,47^{*}$ & $-0,34 *$ \\
\hline MSP & $-0,19^{\text {ns }}$ & $-0,26^{\mathrm{ns}}$ & $-0,20^{\mathrm{ns}}$ & $-0,19^{\text {ns }}$ & $0,53^{*}$ & $-0,22^{\mathrm{ns}}$ & $0,36^{\mathrm{ns}}$ & $-0,19^{\mathrm{ns}}$ \\
\hline $\mathrm{CE}$ & $0,52 *$ & $0,36^{\mathrm{ns}}$ & $-0,18^{\mathrm{ns}}$ & $-0,04^{\mathrm{ns}}$ & $-0,43 *$ & $0,33^{\mathrm{ns}}$ & $-0,60 *$ & $0,04^{\mathrm{ns}}$ \\
\hline EA & $0,32^{\mathrm{ns}}$ & $0,32^{\mathrm{ns}}$ & $-0,22^{\mathrm{ns}}$ & $0,35^{\mathrm{ns}}$ & $0,21^{\mathrm{ns}}$ & $-0,32^{\mathrm{ns}}$ & $-0,48^{*}$ & $0,25^{\mathrm{ns}}$ \\
\hline IVEA & $-0,28^{\mathrm{ns}}$ & $-0,08^{\mathrm{ns}}$ & $-0,08^{\mathrm{ns}}$ & $-0,10^{\text {ns }}$ & $0,73 * *$ & $-0,25^{\mathrm{ns}}$ & $0,45^{*}$ & $-0,07^{\mathrm{ns}}$ \\
\hline $\mathrm{EC}$ & $0,50 *$ & $0,12^{\text {ns }}$ & $0,73 * *$ & $0,20^{\mathrm{ns}}$ & $0,08^{\mathrm{ns}}$ & $0,24^{\mathrm{ns}}$ & $0,43^{*}$ & $0,74 *$ \\
\hline IVEC & $0,05^{\mathrm{ns}}$ & $0,21^{\mathrm{ns}}$ & $0,25^{\mathrm{ns}}$ & $0,09^{\mathrm{ns}}$ & $0,296^{\mathrm{ns}}$ & $0,49 *$ & $0,27^{\mathrm{ns}}$ & $0,31^{\mathrm{ns}}$ \\
\hline
\end{tabular}

SS - envelhecimento acelerado pelo método sem solução saturada de $\mathrm{NaCl}$; $\mathrm{CS}$ - envelhecimento com solução saturada de $\mathrm{NaCl}$ (por 42 e $45^{\circ} \mathrm{C}$ durante 36 e 48 horas); G- germinação; PC- primeira contagem; CP- comprimento de plântulas; MSP- massa seca de plântulas; CE- condutividade elétrica; EA - emergência em areia; IVEA - índice de velocidade de emergência; EC- emergência em campo; IVEC- índice de velocidade de emergência em campo. ${ }^{*}$ significativo em nível de $1 \%$; $*$ significativo em nível de $5 \%$ e ns não significativo pelo teste $\mathrm{t}$

\section{CONCLUSÃO}

O teste de envelhecimento acelerado (com solução de $\mathrm{NaCl}$ sob $45^{\circ} \mathrm{C}$ durante 36 horas) e de deterioração controlada (com sementes pré-umedecidas a $20 \%$ a $45{ }^{\circ} \mathrm{C}$ durante 36 horas), assim como o de emergência de plântulas em campo, foram eficientes na classificação dos lotes de sementes de nabo forrageiro em quatro distintos níveis de vigor.

\section{AGRADECIMENTOS}

Os autores agradecem à CAPES e ao CNPq, pelas bolsas de pesquisa.

\section{REFERÊNCIAS}

ÁVILA, M. R. et al. Testes de laboratório em sementes de canola e a correlação com a emergência das plântulas em campo. Revista Brasileira de Sementes, v. 27, n. 1, p. 62-70, 2005.
BARROS, D. I. et al. Comparação entre testes de vigor para avaliação da qualidade fisiológica de sementes de tomate. Revista Brasileira de Sementes, v. 24, n. 2, p. 12-16, 2002.

BRASIL. Ministério da Agricultura Pecuária e Abastecimento. Instrução Normativa $n^{0}$ 30, de 21 de Maio de 2008. Estabelecer normas e padrões para produção e comercialização de sementes de espécies forrageiras de clima tropical. Disponível em: <http://extranet. agricultura. gov.br/sislegis>. Acesso em: 18 maio 2011.

BRASIL. Ministério da Agricultura e Reforma Agrária. Regras para Análise de Sementes. Brasília: SNDA/DNDV/ CLAV, 2009. 398 p. Disponível em: <http://www.agricultura. gov.br >. Acesso em: 20 out. 2010.

COSTA C. J.; TRZECIAK M. B.; VILLELA F. A. Potencial fisiológico de sementes de brássicas com ênfase no teste de envelhecimento acelerado. Horticultura Brasileira, v. 26, n. 2 , p. 144-148, 2008.

DEMIR, I. et al. Prediction of germination and vigour in naturally aged commercially available seeds lots of cabbage (Brassica oleracea var. capitata) using the bulk conductivity method. Seed Science and Technology, v. 36, n. 3, p. 509-523, 2008. 
FESSEL, S. A. et al. Uso de solução salina $(\mathrm{NaCl})$ no teste de envelhecimento acelerado em sementes de broccolis (Brassica oleracea L. var. italica Plenk). Científica, v. 33, n. 1, p. 27-34, 2005.

GOULART, L. S.; TILLMANN, M. A. A. Vigor de sementes de rúcula (Eruca sativa L.) pelo teste de deterioração controlada. Revista Brasileira de Sementes, v. 29, n. 2, p. 179-186, 2007.

HENNING, F. A. et al. Composição química e mobilização de reservas em sementes de soja de alto e baixo vigor. Bragantia, v. 69, n. 3, p. 727-734, 2010.

KIKUTI, A. L. P.; MARCOS FILHO, J. Physiological potential of cauliflower seeds. Scientia Agrícola, v. 65, n. 4, p. 374-380, 2008.

KOMBA, C. G.; BRUNTON, B. J.; HAMPTON, J. G. Accelerated ageing vigour testing of kale (Brassica oleracea $\mathrm{L}$. var. acephala DC). Seed Science and Techonology, v. 34, n. 2, p. 205-208, 2006.

KRZYZANOWSKI, F. C.; VIEIRA, R. D. Deterioração Controlada. In: KRZYZANOWSKI, F. C.; VIEIRA, R. D.; FRANÇA NETO, J. B. (Ed.) Vigor de sementes: conceitos e testes. Londrina: ABRATES, 1999. cap. VI, p. 1-13.

LARSEN, S. U. et al. The influence of seed vigour on field performance and the evaluation of the applicability of the controlled deterioration vigour test in oil seed rap (Brassica napus) and pea (Pisum sativum). Seed Science and Technology, v. 26, n. 3, p. 627-641, 1998.

LIMA, L. B.; MARCOS FILHO, J. Procedimentos para condução de testes de vigor baseados na tolerância ao estresse térmico em sementes de pepino. Revista Brasileira de Sementes, v. 33, n. 1, p. 45-53, 2011.

MARCOS FILHO, J. Testes de vigor: importância e utilização. In: KRZYZANOWSKI, F. C.; VIEIRA, R. D.; FRANÇA NETO, J. B. (Ed.) Vigor de sementes: conceitos e testes. ABRATES, 1999. cap. I, p. 1-21.

MARCOS FILHO, J.; NOVEMBRE, A. D. C.; CHAMMA, H. M. C. P. Testes de envelhecimento acelerado e de deterioração controlada para avaliação do vigor de sementes de soja. Scientia Agrícola, v. 58, n. 2, p. 421-426, 2001

MATTHEWS, S. et al. Vigour tests for cabbage seeds using electrical conductivity and controlled deterioration to estimative emergence in transplant modules. Seed Science and Technology, v. 37, n. 3, p. 736-746, 2009.

MENDONÇA E. A. F; RAMOS N. P; FESSEL S. A. Adequação da metodologia do teste de deterioração controlada para sementes de brócolis (Brassica oleracea L. var. italica). Revista Brasileira de Sementes, v. 25, n. 1, p. 18-24, 2003.

NAKAGAWA, J. Testes de vigor baseados no desempenho das plântulas. In: KRZYZANOWSKI, F. C.; VIEIRA, R. D.; FRANÇA NETO, J. B. (Ed.) Vigor de sementes: conceitos e testes. Londrina: ABRATES, 1999. cap.II, p. 1-24.

NERY, M. C.; CARVAlho, M. L. M.; GUIMARÃES, R. M. Testes de vigor para avaliação da qualidade fisiológica de sementes de nabo forrageiro. Informativo Abrates, v. 19, n. 2, p. 448, 2009.

RAMOS, N. P. et al. Envelhecimento acelerado em sementes de rúcula (Eruca sativa L.). Revista Brasileira de Sementes, v. 26, n. 1, p. 98-103, 2004.

RIBEIRO JUNIOR, J. I. Análise estatística no SAEG. Viçosa: UFV, 2001. $301 \mathrm{p}$.

ROSSETTO, C. A. V.; FERNANDEZ, E. M.; MARCOS FILHO, J. Metodologias de ajuste do grau de umidade e comportamento das sementes de soja no teste de germinação. Revista Brasileira de Sementes, v. 17, p. 171-178, 1995.

ROSSETTO, C. A. V.; MARCOS FILHO, J. Comparação entre métodos de envelhecimento acelerado e de deterioração controlada para avaliação da qualidade fisiológica de sementes de soja. Scientia Agricola, v. 52, n. 1, p. 123-131, 1995.

SOUZA, A. D. V. et al. Caracterização química de sementes e tortas de pinhão manso, nabo forrageiro e crambé. Pesquisa Agropecuária Brasileira, v. 44, n. 10, p. 1328-1335, 2009.

TEKRONY, D. M. Precision is an essential component in seed vigour testing. Seed Science and Technology. v. 31, n. 2, p. 435447, 2003.

TORRES, S. B.; PEREIRA, R. A. Condutividade elétrica em sementes de rúcula. Revista Brasileira de Sementes, v. 32, n. 4, p. 58-70, 2010.

VERMA, S. S; VERMA, U.; TOMER, R. P. S. Studies on seed quality parameters in deteriorating seeds in brassica (Brassica campestres). Seed Science and Technology. v. 31, n. 2, p. 389-396, 2003. 